\title{
Effect of Acetic Acid on Wear Properties of Ferrous and Titanium-Based Materials under Ethanol Lubrication
}

\author{
Yuko Hibi and Hiroki Mano \\ National Institute of Advanced Industrial Science and Technology (AIST), Tsukuba 305-8564, Japan
}

Disks of ferrous and titanium-based material were immersed and unidirectionally slid against a stainless steel pin in ethanol with or without acetic acid to evaluate the effect of acetic acid on wear. The disks were made of cast iron, stainless steel, titanium metal and particulate-reinforced titanium metal matrix composite sintered from mixed powder of $\mathrm{Si}_{3} \mathrm{~N}_{4}(5 \mathrm{mass} \%)$, TiN (10 mass \%) and Ti ( 85 mass $\left.\%\right)$. In the absence of sliding, the stainless steel, titanium and composite showed good corrosion resistance but the cast iron exhibited galvanic corrosion. With sliding, the addition of acetic acid to the ethanol increased the wear of the ferrous materials but had little effect on the titanium-based materials. Morphological and chemical analyses of the worn surfaces revealed that acetic acid promoted anodic dissolution of iron on the sliding surfaces of the ferrous materials in ethanol. The results also indicated that titanium and the composite in ethanol with and without acetic acid primary underwent mechanical wear and chemical wear, respectively. The composite exhibited good corrosion and wear resistance in ethanol regardless of the presence of acetic acid. [doi:10.2320/matertrans.MT-M2020103]

(Received March 27, 2020; Accepted September 24, 2020; Published November 25, 2020)

Keywords: cast iron, stainless steel, titanium, composite, wear, ethanol, acetic acid

\section{Introduction}

The purpose of this study was to develop wear-resistant materials for use with fuel based on renewable ethanol derived from plant biomass. At present, ferrous materials such as cast iron and carbon steel are typically employed in petroleum fuel pipelines and storage tanks. However, corrosive impurities such as sodium chloride and acetic acid can be found in fuel-grade biomass ethanol, the latter of which was the focus of this research. ${ }^{1-3)}$ Many other groups have previously investigated the corrosive effects of acetic acid on ferrous materials immersed in fuel grade ethanol. ${ }^{1,4-8)}$

In solution, acetic acid can dissociate into acetate anions and protons (Scheme (1)). ${ }^{9)}$

$$
\left.\mathrm{CH}_{3} \mathrm{COOH} \leftrightarrows \mathrm{CH}_{3} \mathrm{COO}^{-}+\mathrm{H}^{+} \quad \text { Scheme (1) }\right)^{9)}
$$

In ethanol, the dissociation of acetic acid is promoted because the acetate anion is stabilized by the polar protic solvent. ${ }^{5,9)}$ The resulting ions act as electrolytes and can cause anodic dissolution of iron from ferrous materials. ${ }^{1)} \mathrm{The} \mathrm{Fe}^{2+}$ ions produced by this process subsequently react with acetate anions to form iron acetate $\left(\left(\mathrm{CH}_{3} \mathrm{COO}\right)_{2} \mathrm{Fe}\right)$, which is soluble in ethanol (Scheme (2)). ${ }^{1)}$

$$
\begin{aligned}
2 \mathrm{CH}_{3} \mathrm{COOH}+\mathrm{Fe} & \rightarrow 2 \mathrm{CH}_{3} \mathrm{COO}^{-}+2 \mathrm{H}^{+}+\mathrm{Fe}^{2+}+2 \mathrm{e}^{-} \\
& \rightarrow\left(\mathrm{CH}_{3} \mathrm{COO}\right)_{2} \mathrm{Fe}+\mathrm{H}_{2} \quad \text { Scheme }(2)^{1)}
\end{aligned}
$$

A passivation film consisting of $\gamma-\mathrm{Fe}_{2} \mathrm{O}_{3}$ and $\mathrm{Fe}_{3} \mathrm{O}_{4}$ is typically formed on iron surface and it has been reported that acetic acid damages this iron oxide film., ${ }^{1,7,10)}$ Goodmann et al. reported that acetic acid in fuel grade ethanol inhibited the repassivation of steel, while Samusawa et al. found that acetic acid disrupted the iron oxide film on carbon steel immersed in fuel grade ethanol. ${ }^{1,7)}$ When this iron oxide film is ruptured, anodic dissolution of the underlying metal iron occurs. ${ }^{1)}$ In addition, the galvanic corrosion of cast iron can proceed as a result of the difference in potential between the material components (that is, between graphite, cementite and ferrite). ${ }^{11)}$ This corrosion can lead to serious problems, including loss of strength as well as cracking and pitting. ${ }^{1-4)}$
The equipment that used to transport biomass ethanol fuel incorporates moving parts such as pistons and cylinders, and the materials of which these are made must be resistant to corrosion and wear when in contact with the fuel. However, there has been little research focusing on the wear resistance of materials in ethanol containing corrosive impurities such as acetic acid. Therefore, the present work investigated the wear behavior of various materials in ethanol with and without acetic acid.

Stainless steel and titanium metal are known to show a high degree of resistance to corrosion by acetic acid. ${ }^{12)} \mathrm{A}$ chromium oxide $\left(\mathrm{Cr}_{2} \mathrm{O}_{3}\right)$ rich-iron oxide $\left(\mathrm{Fe}_{2} \mathrm{O}_{3}\right)-\mathrm{Cr}_{2} \mathrm{O}_{3}$ film forms on the surface of stainless steel, while titanium oxide $\left(\mathrm{TiO}_{2}\right)$ film forms on the surface of titanium, both of which are excellent passivation layers. ${ }^{13-17)}$ However, the wear resistance of titanium and its alloys is poor. ${ }^{18,19)}$ It is often possible to improve the wear resistance of such materials by the addition of particulate reinforcements. ${ }^{20-30)}$ As an example, our own group previously reported that the wear resistance of titanium metal matrix composites produced by sintering a mixture of $\mathrm{Si}_{3} \mathrm{~N}_{4}, \mathrm{TiN}$ and $\mathrm{Ti}$ powders was much higher than that of titanium metal. ${ }^{28,29)}$ On this basis, we considered that a particulate-reinforced titanium metal matrix composite could perform well during sliding tests in biomass-based ethanol.

In the present work, immersion and sliding tests were performed using cast iron, stainless steel, titanium metal and particulate-reinforced titanium metal matrix composite specimens in ethanol both with and without acetic acid, to evaluate wear resistance. The effect of acetic acid on the wear of the test materials are discussed herein based on the analysis of specific wear rates as well as the morphologies and chemical compositions of the specimen surfaces.

\section{Experimental}

\subsection{Test materials}

The test specimens were disks (diameter: $20 \mathrm{~mm}$, thickness: $5 \mathrm{~mm}$ ) made of FC250 cast iron, SUS440C stainless steel, 
Table 1 Physical properties of the materials tested in this work.

\begin{tabular}{lccc}
\hline \multirow{2}{*}{ Material } & $\begin{array}{c}\text { Vickers hardness, } \\
H v / \mathrm{GPa}\end{array}$ & $\begin{array}{c}\text { Young's } \\
\text { modulus, } \\
E / \mathrm{GPa}\end{array}$ & $\begin{array}{c}\text { Poisson's } \\
\text { ratio }\end{array}$ \\
\hline FC250 Cast iron & 1.9 & $110^{* 31)}$ & $0.3^{* 31)}$ \\
\hline $\begin{array}{c}\text { SUS440C } \\
\text { Stainless steel }\end{array}$ & Pin: 3.9 & $204^{* *}$ & $0.3^{* 32}$ \\
\cline { 2 - 3 } Disk: $7.1^{* *}$ & $116^{* 33)}$ & $0.3^{* 33)}$ \\
\hline Ti Metal & 1.4 & 170 & - \\
\hline 5-10-85 Composite & 9.1 & & \\
* Literature value & & & \\
* Catalogue value & & &
\end{tabular}

Table 2 Chemical compositions of the ferrous materials employed in this work.

\begin{tabular}{lccccccccccc}
\hline \multicolumn{10}{c}{ Atomic ratio, /atomic\% } \\
\hline & $\mathrm{C}$ & $\mathrm{Si}$ & $\mathrm{Mn}$ & $\mathrm{P}$ & $\mathrm{S}$ & $\mathrm{Cu}$ & $\mathrm{Ni}$ & $\mathrm{Cr}$ & $\mathrm{Mo}$ & $\mathrm{Fe}$ \\
\hline $\begin{array}{l}\text { SUS440C } \\
\begin{array}{l}\text { Stainless steel } \\
\text { Pin }\end{array}\end{array}$ & 1.01 & 0.18 & 0.25 & 0.002 & 0.001 & - & 0.22 & 16.3 & 0.37 & bal. \\
\hline $\begin{array}{l}\text { SUS440C } \\
\begin{array}{l}\text { Stainless steel } \\
\text { Disk }\end{array}\end{array}$ & 1.04 & 0.15 & 0.37 & 0.026 & 0.001 & - & 0.16 & 16.1 & 0.37 & bal. \\
\hline $\begin{array}{l}\text { FC250 Cast } \\
\text { iron Disk }\end{array}$ & 3.48 & 3.09 & 0.34 & 0.015 & 0.01 & - & - & - & - & bal. \\
\hline
\end{tabular}

titanium metal (purity $>99.7 \%$ ) and particulate-reinforced titanium metal matrix composite and hemispherical pin (radius: $2 \mathrm{~mm}$ ) made of SUS440C stainless steel. The particulate-reinforced titanium metal matrix composite disks were prepared from a powder mixture comprising 5 mass $\%$ $\mathrm{Si}_{3} \mathrm{~N}_{4}, 10$ mass $\%$ TiN and 85 mass $\%$ Ti by spark plasma sintering at $1573 \mathrm{~K}^{30}$ ) Hereafter, this material is referred to as the 5-10-85 composite. The surfaces of the 5-10-85 composite disks were polished using a no. 1000 grade diamond-grinding wheel, and chemical analysis of the 510-85 composite was performed by X-ray photoelectron spectroscopy (XPS, Theta Probe XPS system, Thermo Fisher Scientific). The physical properties of the materials and the chemical composition of the ferrous materials are summarized in Tables 1 and 2, respectively. ${ }^{31-33)}$ The lubricants employed were dehydrated ethanol $\left(\mathrm{C}_{2} \mathrm{H}_{5} \mathrm{OH}, 99.5 \%\right.$, $\mathrm{H}_{2} \mathrm{O}<50 \mathrm{ppm}$ ) and a 5 vol\% solution of acetic acid in ethanol. To accelerate corrosion of the tested materials, the concentration of acetic acid in the lubricant was much higher than that in fuel-grade biomass ethanol. ${ }^{1-3)}$

\subsection{Immersion test}

To evaluate the effect of adding acetic acid to the ethanol on the morphologies and chemical composition of the specimen surfaces under the condition not involving sliding, immersion tests were performed. In the immersion test, disks of the FC250 cast iron, SUS440C stainless steel, titanium metal and 5-10-85 composite were immersed in ethanol with and without acetic acid for approximately $7 \mathrm{~h}$ at room temperature, after which the disks were rinsed with ethanol and dried in air.

\subsection{Sliding test}

Sliding tests were performed using a unidirectional pin-on- disk machine (FPR-2100, RHESCA), which has been described elsewhere. ${ }^{34)}$ Disks of FC250 cast iron, SUS440C stainless steel, titanium metal and the 5-10-85 composite were slid against SUS440C stainless steel hemispherical pins in ethanol with and without acetic acid with an applied load of $0.49 \mathrm{~N}$, sliding speed of $40 \mathrm{~mm} / \mathrm{s}$, sliding time of $100 \mathrm{~min}$ and sliding distance of $240 \mathrm{~m}$. The initial mean Hertzian contact pressures between the stainless steel pin and the cast iron, stainless steel and titanium metal disks were $0.35,0.45$ and $0.36 \mathrm{GPa}$, respectively. The initial mean Hertzian contact pressure between the stainless steel pin and the 5-10-85 composite disk was $0.42 \mathrm{GPa}$, assuming that the Poisson's ratio of the 5-10-85 composite was 0.3 . The sliding tests were performed with high PV (pressure-velocity) values $(14 \sim 18 \mathrm{MPa} \cdot \mathrm{m} / \mathrm{s})$ to accelerate wear. Each test was performed three times. After the sliding test, the disk and pin were rinsed with ethanol and then dried in air.

The wear volume of the pin $(V(\operatorname{pin}))$ was calculated from the wear diameter using the eq. $(1)^{35)}$

$$
V(\text { pin })=\pi d^{4} /(64 r)
$$

where

$d$ is the wear scar diameter and

$r$ is the radius of the hemispherical pin $(2 \mathrm{~mm}) .{ }^{35)}$

The wear volume of the disk was approximated by the product of the mean area of 10 cross-sections of a wear track and the circumferential length of the wear track.

\subsection{Surface observation}

The surface roughness $(R a)$ of each immersed disk and cross-sections of the wear track on the disk were examined using a stylus-type surface texture and contour measurement instrument (SURFCOM 1500, TOKYO SEIMITSU). Threedimensional (3D) profiles of the sliding surfaces of the pins and the disks were acquired with a laser microscope (VK-9500, KEYENCE). The morphologies and chemical compositions of the surfaces of disks and pins were assessed by tungsten filament scanning electron microscopy (WSEM, JSM-6060, JEOL: accelerating voltage; $6 \mathrm{kV}$ ) and energy-dispersive X-ray spectroscopy (EDS, JED-2300, JEOL: accelerating voltage; $10 \mathrm{kV}$ ), respectively. The chemical analyses of the wear tracks of the 5-10-85 composite disks were performed using XPS after $\mathrm{Ar}^{+}$ion etching for $30 \mathrm{~s}$.

\section{Results and Discussion}

\subsection{Structure of the 5-10-85 composite}

Figure 1 shows EDS images of a 5-10-85 composite surface before wear testing. Several pits on the surface of the 5-10-85 composite had formed during sintering and polishing process (Fig. 1(a)). In the EDS maps presented here, brighter regions have a higher concentration of the element being assessed, and both $\mathrm{Si}$ and $\mathrm{Ti}$ rich areas can be seen (Figs. 1(b) and 1(c)). During sintering of this material, the $\mathrm{Si}_{3} \mathrm{~N}_{4}$ would be expected to react with titanium to produce titanium silicide $\left(\mathrm{TiSi}_{\mathrm{x}}\right)$ such as $\mathrm{Ti}_{5} \mathrm{Si}_{3}$ and $\mathrm{TiSi}_{2}$, at high temperatures. ${ }^{30,36,37)}$ Figure 2 presents the Si 2 p peak profile of a 5-10-85 composite disk as obtained by XPS after $\mathrm{Ar}^{+}$ion etching for $1000 \mathrm{~s}$. The binding energy values of 
(a) Image
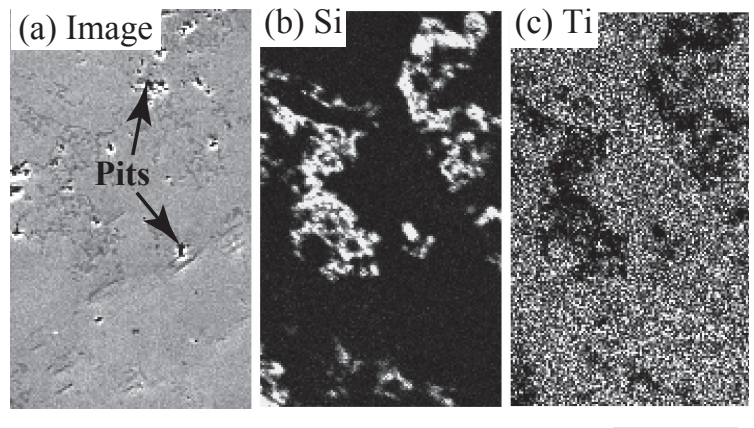

$30 \mu \mathrm{m}$

Fig. 1 EDS images of the 5-10-85 composite surface: (a) a secondary electron image, (b) a Si K $\alpha$ map and (c) a Ti K $\alpha$ map. Brighter contrast indicates a higher concentration of the element.

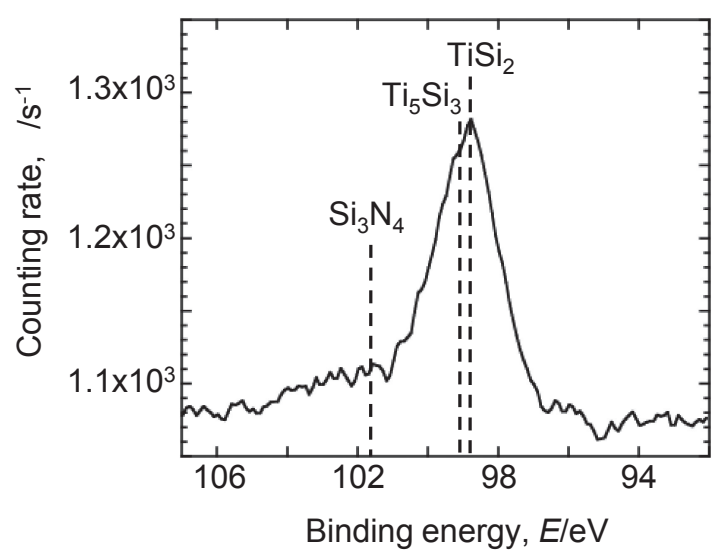

Fig. 2 The Si 2 p peak profile obtained from the 5-10-85 composite using XPS.

$\mathrm{Si}_{3} \mathrm{~N}_{4}, \mathrm{Ti}_{5} \mathrm{Si}_{3}$ and $\mathrm{TiSi}_{2}$ are reported to be 101.7, 99.1 and $98.8 \mathrm{eV}$, respectively. ${ }^{38,39)}$ XPS spectrum indicates that the $\mathrm{Si}$ in the $5-10-85$ composite was primarily present as $\mathrm{Ti}_{5} \mathrm{Si}_{3}$ and $\mathrm{TiSi}_{2}$.

\subsection{Effect of acetic acid on surface properties in the absence of sliding}

Figure 3 and Table 3 present the SEM images and the chemical composition and surface roughness values $(R a)$ of test specimens after immersion in ethanol with and without acetic acid, respectively. The surface of the FC250 cast iron disk after immersion in ethanol is smooth, and the dark grey areas in the image are attributed to graphite (Fig. 3(a)). In contrast, protruding white lamellar structures and hollows around the graphite flakes can be observed on the surface of the FC250 cast iron disk immersed in ethanol with added acetic acid (Fig. 3(e)). These white lamellae appear to be made of cementite $\left(\mathrm{Fe}_{3} \mathrm{C}\right)$ in perlite, and the protruding lamellar structure was likely formed by galvanic corrosion between the cementite and iron. ${ }^{11,40)}$ The hollows appear to have resulted from galvanic corrosion between graphite and iron. ${ }^{11)}$ Because of these protrusions and hollows, the $R a$ of the FC250 cast iron disk immersed in ethanol containing acetic acid was larger than that of the sample placed in the pure ethanol. The surface morphologies of the disks of the other materials were essentially the same following exposure to either pure ethanol or ethanol with acetic acid (Fig. 3). In addition, there were only minimal variations in the chemical compositions of the surfaces of the test specimens immersed in ethanol with and without acetic acid (Table 3).

\subsection{Characterizations of the worn surfaces and specific wear rates}

Figures 4 and 5 show topographic images of the worn disk surfaces of ferrous materials and titanium-based materials, respectively. In each topographic image, brighter regions indicate higher positions and a cross sectional profile along the white horizontal line is shown.

The wear tracks of the ferrous materials worn in ethanol containing acetic acid were wider and deeper than those worn in ethanol (Fig. 4). The wear track of the FC250 cast iron disk worn in ethanol was groove shaped (Fig. 4(a)) and that worn in ethanol solution containing acetic acid was rough

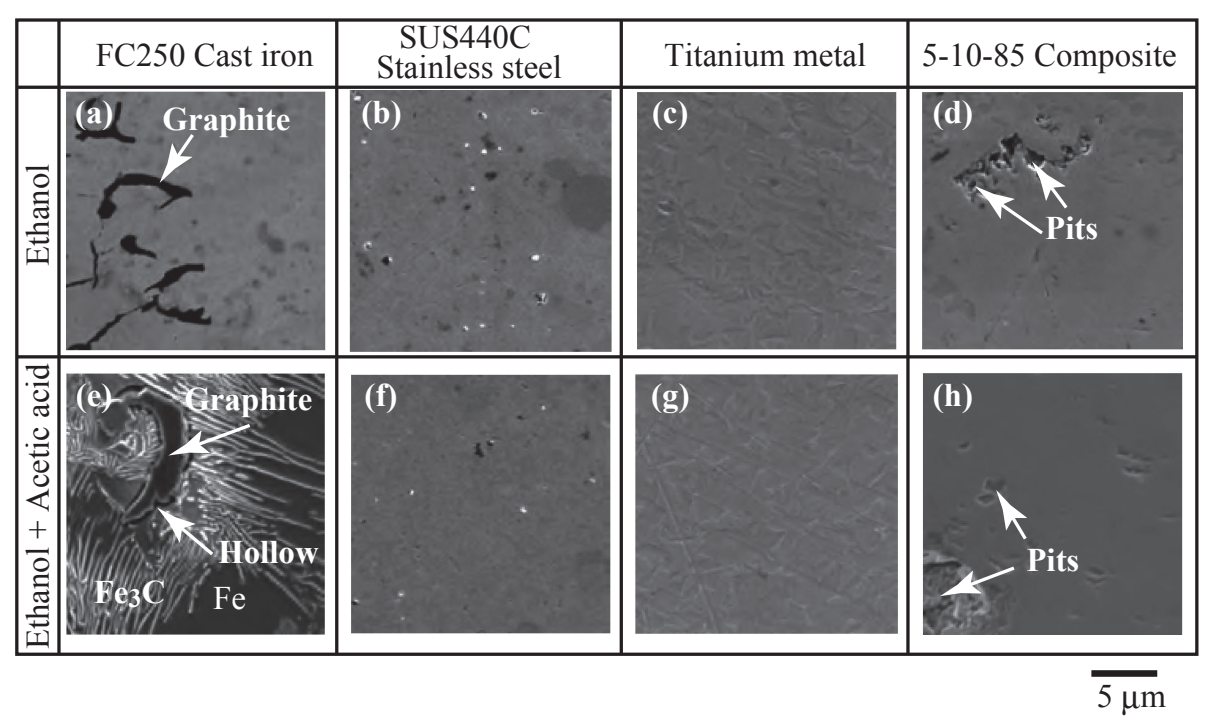

Fig. 3 SEM images of test specimens after immersion tests: the (a) FC250 cast iron disk, (b) SUS440C stainless steel disk, (c) titanium metal disk and (d) 5-10-85 composite disk after immersion in ethanol and the (e) FC250 cast iron disk, (f) SUS440C stainless steel disk, (g) titanium metal disk and (h) 5-10-85 composite disk after immersion in ethanol solution containing acetic acid. 
Table 3 Chemical composition and surface roughness $(R a)$ of the test specimens after the immersion test.

\begin{tabular}{|c|c|c|c|c|c|c|c|c|}
\hline \multirow{2}{*}{ Material } & \multirow{2}{*}{ Immersion liquid } & \multicolumn{6}{|c|}{ Atomic ratio, /atomic $\%$} & \multirow{2}{*}{ 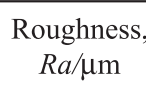 } \\
\hline & & $\mathrm{C}$ & $\mathrm{O}$ & $\mathrm{Si}$ & $\mathrm{Ti}$ & $\mathrm{Cr}$ & $\mathrm{Fe}$ & \\
\hline \multirow{2}{*}{ FC250 Cast iron } & Ethanol & 4.97 & - & 4.51 & - & 0.31 & 90.21 & 0.020 \\
\hline & Ethanol + Acetic acid & 5.63 & 2.11 & 5.19 & - & 0.21 & 86.87 & 0.130 \\
\hline \multirow{2}{*}{$\begin{array}{c}\text { SUS440C } \\
\text { Stainless steel }\end{array}$} & Ethanol & 4.46 & 1.86 & 一 & - & 10.92 & 82.75 & 0.008 \\
\hline & Ethanol + Acetic acid & 5.23 & 1.07 & 一 & 一 & 9.88 & 83.82 & 0.008 \\
\hline \multirow{2}{*}{ Ti Metal } & Ethanol & - & - & - & 99.96 & 一 & 0.04 & 0.009 \\
\hline & Ethanol + Acetic acid & 1.17 & - & 0.00 & 98.83 & - & 一 & 0.008 \\
\hline \multirow{2}{*}{$\begin{array}{c}\text { 5-10-85 } \\
\text { Composite }\end{array}$} & Ethanol & - & - & 1.21 & 98.71 & - & 0.08 & 0.058 \\
\hline & Ethanol + Acetic acid & - & 一 & 1.33 & 98.67 & 一 & - & 0.059 \\
\hline
\end{tabular}

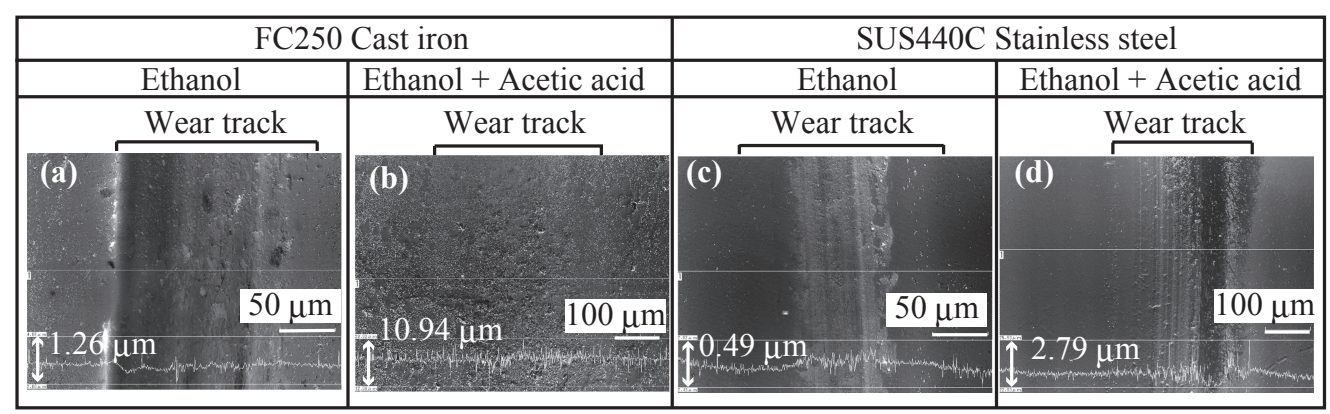

Fig. 4 Topographic images of the worn surfaces of disks of ferrous materials: FC250 cast iron disks worn in (a) ethanol and (b) ethanol solution containing acetic acid, SUS440C stainless steel disks worn in (c) ethanol and (d) ethanol solution containing acetic acid. Brighter contrast in each topographic image indicates a greater height.

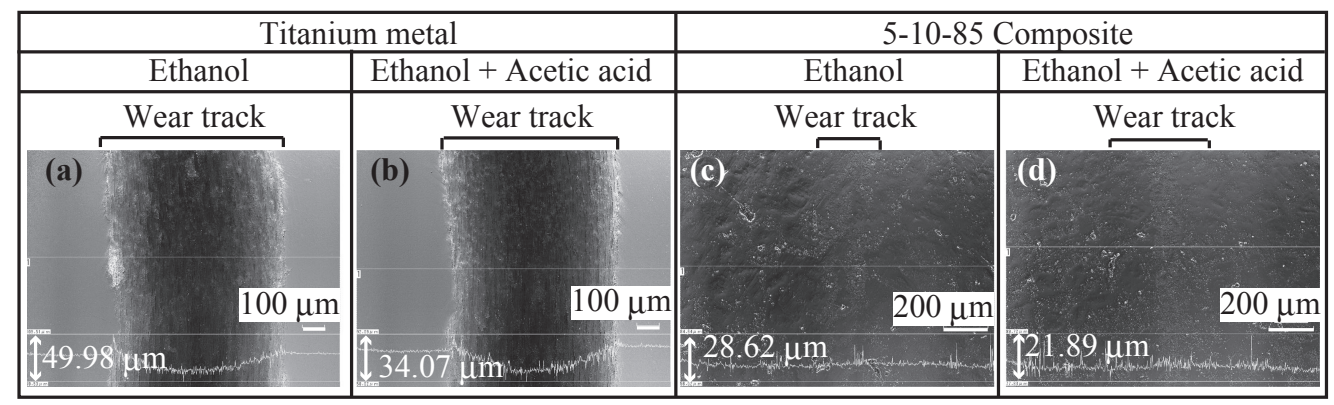

Fig. 5 Topographic images of the worn disk surfaces of titanium-based materials: titanium metal disks worn in (a) ethanol and (b) ethanol solution containing acetic acid, 5-10-85 composite disks worn in (c) ethanol and (d) ethanol solution containing acetic acid. Brighter contrast in each topographic image indicates a greater height.

(Fig. 4(b)). Ridges can be seen in the middle of the wear track of the SUS440C stainless steel disk worn in ethanol (Fig. 4(c)) while grooves are apparent on the wear track of the SUS440C stainless steel disk worn in ethanol solution containing acetic acid (Fig. 4(d)).

Deep grooves are present in the wear tracks of the titanium metal disks worn in ethanol both with and without acetic acid (Figs. 5(a) and (b)). In the case of the 5-10-85 composite disks worn in ethanol with and without acetic acid, there are no evident differences in the surface configurations between worn and unworn surfaces (Figs. 5(c) and (d)).

Figure 6 summarizes the specific wear rates of the disks and pins, and provides error bars representing the standard deviation. In each case, the specific wear rate of the disk was calculated from the volume below the unworn surface. The wear of the disk of the ferrous materials in ethanol solution containing acetic acid were larger than those in ethanol. In particular, the specific wear rate of the SUS440C stainless steel disk in ethanol solution containing acetic acid was $c a .57$ times as large as that in ethanol. The wear of titanium metal disk in ethanol and that in ethanol solution containing acetic acid were significantly large and about the same value. The wear volumes of the 5-10-85 composite disks in ethanol and in ethanol solution containing acetic acid were too small to be calculated using the cross-sectional area of the wear track.

Flat wear scars were observed on the sliding surfaces of SUS440C stainless steel pins slid against FC250 cast iron, SUS440C stainless steel and the 5-10-85 composite disks (data not shown). In contrast, titanium metal adhered on the hemispherical surface of the SUS440C stainless steel pins slid against titanium metal disks (data not shown). Therefore, the wear volume of pins slid against titanium metal disks could not be calculated. The wear of pins slid against FC250 cast iron, SUS440C stainless steel and the 5-10-85 composite disks in ethanol solution containing acetic acid was larger than that in ethanol. 
(a) Disk

Ethanol

Ethanol + Acetic acid

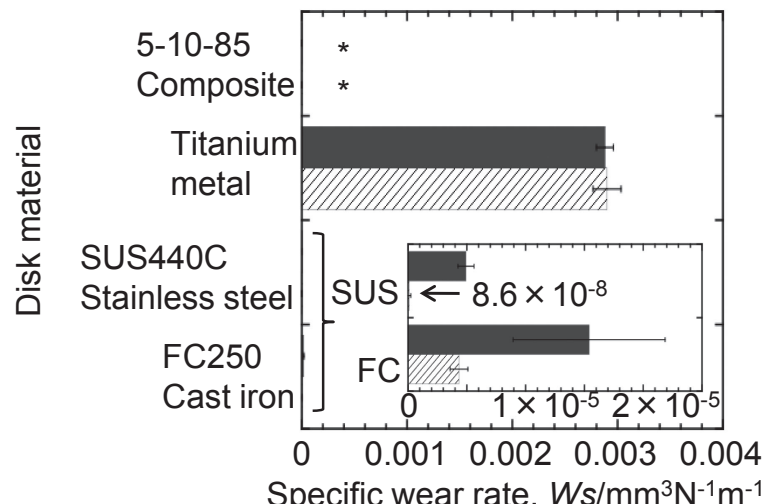

(b) SUS440C Stainless steel pin

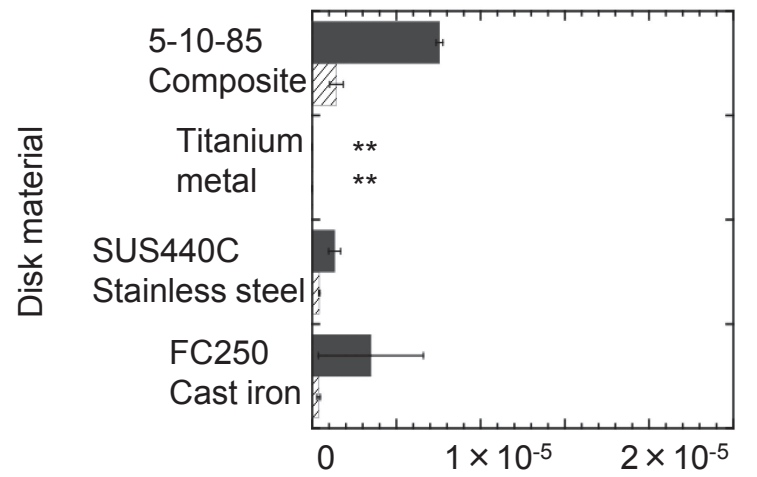

Specific wear rate, $W s / \mathrm{mm}^{3} \mathrm{~N}^{-1} \mathrm{~m}^{-1}$

Fig. 6 Specific wear rates of disks and pins: (a) disk and (b) SUS440C stainless steel pin. The symbols "**" and "***" indicate that the wear could not be calculated.

\subsection{Morphological and chemical analyses of worn surfaces}

\subsubsection{Ferrous materials}

Figures 7 and 8 provide SEM and EDS images of the worn surfaces of FC250 cast iron and those of SUS440C stainless steel disks, respectively. Table 4 summarizes the chemical composition of the metallic area of FC250 cast iron disks and SUS440C stainless steel disks after the sliding test in ethanol with and without acetic acid. In this section, the data in Table 3 are treated as data of unworn surfaces.

The surface of the FC250 cast iron disk worn in ethanol exhibits plastic deformation (Fig. 7(a)) and a reduced concentration of $\mathrm{C}$ (Fig. 7(b)). These results indicate that plastically deformed iron covered the graphite on the surface of the FC250 cast iron disk worn in ethanol. An increased O concentration (Fig. 7(c), Tables 3 and 4) was also observed on the disk surface worn in ethanol. The sliding surface exhibits a high chemical activity because the mechanical energy due to friction generates frictional heat, dangling bond and fresh surface. ${ }^{41)}$ The chemical reaction induced by friction is termed tribochemical reaction. Tribo-oxidation is a tribochemical reaction in which sliding materials were oxidized by oxidizing agents such as oxygen to form oxides on the sliding surface. ${ }^{42)}$ It has been reported that iron oxides $\left(\mathrm{Fe}_{2} \mathrm{O}_{3}\right.$ and $\left.\mathrm{Fe}_{3} \mathrm{O}_{4}\right)$ are produced by tribo-oxidation on the sliding surfaces of ferrous materials in the presence of oxygen

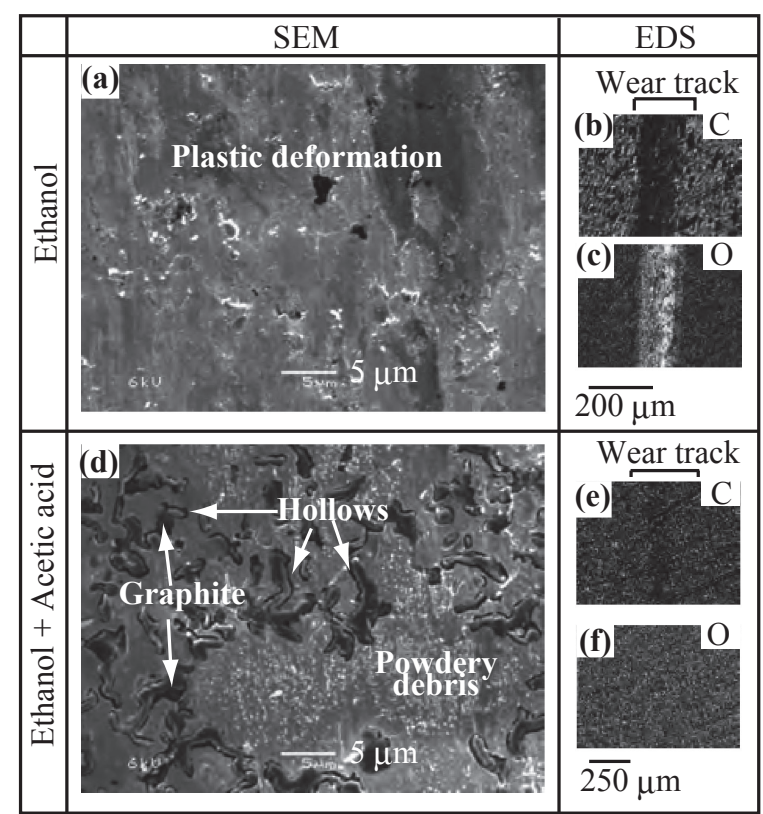

Fig. 7 SEM images and EDS maps of the surfaces of FC250 cast iron disks: (a) SEM image, (b) $\mathrm{C} \mathrm{K} \alpha$ map and (c) O K $\alpha$ map of the disk worn in ethanol and (d) SEM image, (e) $\mathrm{C} \mathrm{K} \alpha$ map and (f) $\mathrm{O} \mathrm{K} \alpha$ map of the disk worn in ethanol solution containing acetic acid. Brighter contrast in the EDS maps indicates a higher concentration of the element.

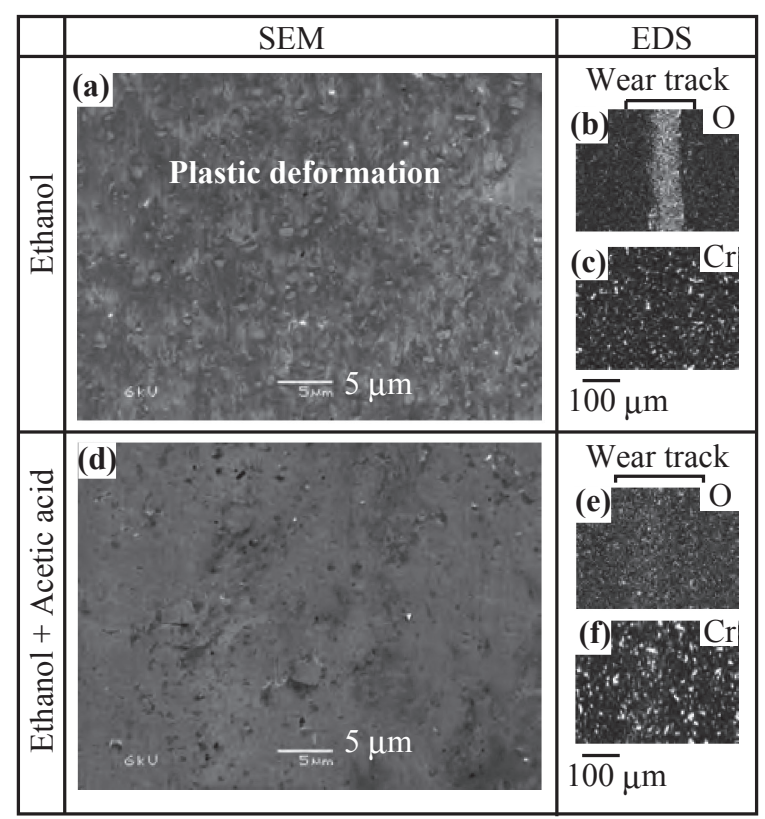

Fig. 8 SEM images and EDS maps of the surfaces of SUS440C stainless steel disks: (a) SEM image, (b) $\mathrm{O} \mathrm{K} \alpha$ map and (c) $\mathrm{Cr} \mathrm{K} \alpha$ map of the disk worn in ethanol and (d) SEM image, (e) O K $\alpha$ map and (f) $\mathrm{Cr} \mathrm{K} \alpha$ map of the disk worn in ethanol solution containing acetic acid. Brighter contrast in the EDS maps indicates a higher concentration of the element.

Table 4 Chemical compositions of the worn surfaces of disks of the ferrous materials.

\begin{tabular}{ccccccc}
\hline \multirow{2}{*}{ Material } & \multirow{2}{*}{ Lubricant } & \multicolumn{5}{c}{ Atomic ratio, atomic\% } \\
\cline { 2 - 7 } & & $\mathrm{C}$ & $\mathrm{O}$ & $\mathrm{Si}$ & $\mathrm{Cr}$ & $\mathrm{Fe}$ \\
\hline \multirow{2}{*}{$\begin{array}{c}\text { FC250 Cast } \\
\text { iron }\end{array}$} & Ethanol & 5.53 & 15.04 & 3.8 & 0.2 & 75.42 \\
\cline { 2 - 7 } & Ethanol + Acetic acid & 5.49 & - & 3.97 & 0.08 & 90.45 \\
\hline SUS440C & Ethanol & 4.38 & 15.23 & - & 16.35 & 64.04 \\
\cline { 2 - 7 } Stainless steel & Ethanol + Acetic acid & 5.76 & 2.21 & - & 16.25 & 75.78 \\
\hline
\end{tabular}


and that iron can react with alcohols to form iron alkoxides that are only slightly soluble in alcohols. ${ }^{43-47)}$ The iron oxide was obtained by the hydrolysis of the iron alkoxide. ${ }^{4,48)}$ In our experiment, it appears that iron oxides were formed by the tribochemical reaction of iron with dissolved oxygen in the ethanol and/or with the ethanol itself. ${ }^{8)}$

The surface of the FC250 cast iron disk worn in ethanol solution containing acetic acid shows numerous hollows around the graphite flakes in addition to powdery debris (Fig. 7(d)). The hollows may have resulted from a galvanic corrosion between iron and graphite. ${ }^{8,11)}$ The hard and brittle cementite lamellae were protruded by the galvanic corrosion. ${ }^{11,49)}$ The powdery debris seemed to be the cementite fractured by sliding. The $\mathrm{C}$ and $\mathrm{O}$ concentrations of the worn and unworn surfaces of the FC250 cast iron disks in ethanol solution containing acetic acid were almost the same (Figs. 7(e) and 7(f)). On the worn FC250 cast iron disk surface, O was hardly detected (Table 4). Galvanic corrosion seemed to occur in preference to the reaction of iron with oxygen and ethanol on the sliding surface of the FC250 cast iron disk in ethanol solution containing acetic acid.

The surface of the SUS440C stainless steel disk worn in ethanol was plastically deformed (Fig. 8(a)) and oxidized (Fig. 8(b), Tables 3 and 4). The ridges in the middle of the wear track (Fig. 4(c)) appear to have been formed by the plastic deformation of the SUS440C stainless steel, while the oxidation of the sliding surface is ascribed to the reaction of iron with oxygen dissolved in ethanol and/or with the ethanol itself. ${ }^{4,43-48)}$ The $\mathrm{Cr}$ concentrations on the worn and unworn surfaces were almost the same (Fig. 8(c)).

The surface of the SUS440C stainless steel disk worn in ethanol solution containing acetic acid was relatively smooth (Fig. 8(d)), and the $\mathrm{O}$ and $\mathrm{Cr}$ concentrations on the worn and unworn surfaces were almost the same (Figs. 8(e) and 8(f)). The addition of acetic acid to the ethanol resulted in increase of wear (Fig. 6(a)). These results suggest that dissolution of the sliding surface of the SUS440C stainless steel disk occurred in ethanol solution containing acetic acid.

Figure 9 shows SEM images of SUS440C stainless steel pins slid against ferrous materials. The SUS440C stainless steel pins slid against the FC250 cast iron disk and the SUS440C stainless steel disk in ethanol show oxygen-rich areas (dark area in Figs. 9(a) and 9(c)). Grooves can be observed on the worn surface of the pin slid against an FC250 cast iron disk in ethanol with acetic acid (Fig. 9(b)). The grooves were evidently formed by the abrasive action of the protruding and fractured cementite in the FC250 cast iron. The worn surface of the SUS440C stainless steel pin slid against the SUS440C stainless steel disk in the ethanol solution containing acetic acid was relatively smooth (Fig. 9(d)).

\subsubsection{Titanium-based materials}

Figures 10 and 11 present SEM and EDS images of the worn surfaces of titanium metal and 5-10-85 composite disks. Table 5 summarizes the chemical compositions of these specimens after sliding test in ethanol both with and without acetic acid. Figure 12 provides SEM images of SUS440C stainless steel pins slid against the titanium-based materials.

Many grooves and adhesive substances can be observed on the titanium metal disk surfaces worn in ethanol with and

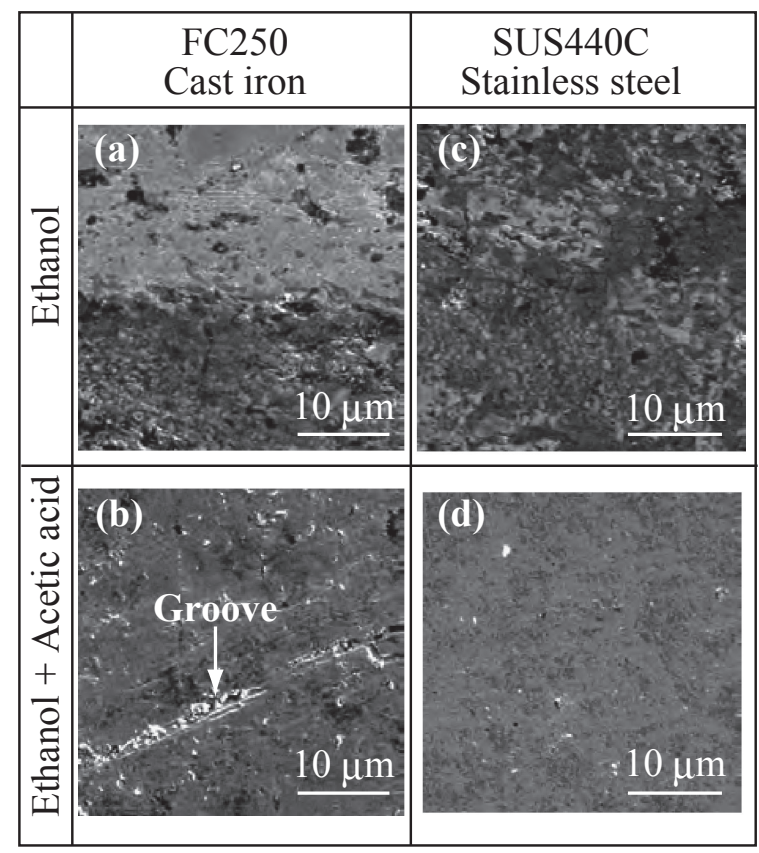

Fig. 9 SEM images of SUS440C stainless steel pin slid against ferrous materials: SEM images of pins slid against FC250 cast iron disk in (a) ethanol and (b) ethanol solution containing acetic acid and SEM images of pins slid against SUS440C stainless steel disk in (c) ethanol and (d) ethanol solution containing acetic acid.

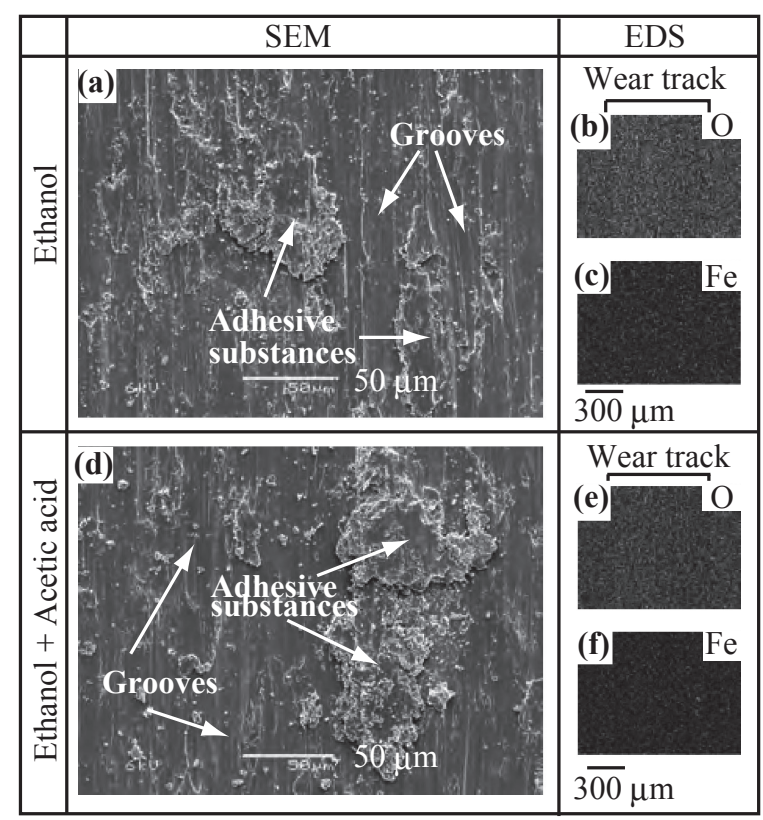

Fig. 10 SEM images and EDS maps of the surfaces of titanium metal disks: (a) SEM image, (b) O K $\alpha$ map and (c) Fe K $\alpha$ map of the disk worn in ethanol and (d) SEM image, (e) O K $\alpha$ map and (f) Fe K $\alpha$ map of the disk worn in ethanol solution containing acetic acid. Brighter contrast in the EDS maps indicates a higher concentration of the element.

without acetic acid (Figs. 10(a) and 10(d)). These features are believed to have been produced by the cutting action of the mating pin and the adhesion of titanium metal to the mating pin, respectively. On the worn titanium metal disk surfaces, $\mathrm{O}$ and Fe were hardly detected (Figs. 10(b), 10(c), 10(e) and 10(f), Table 5). Titanium metal adhered to the surfaces of the SUS440C stainless steel pin slid against the titanium metal 


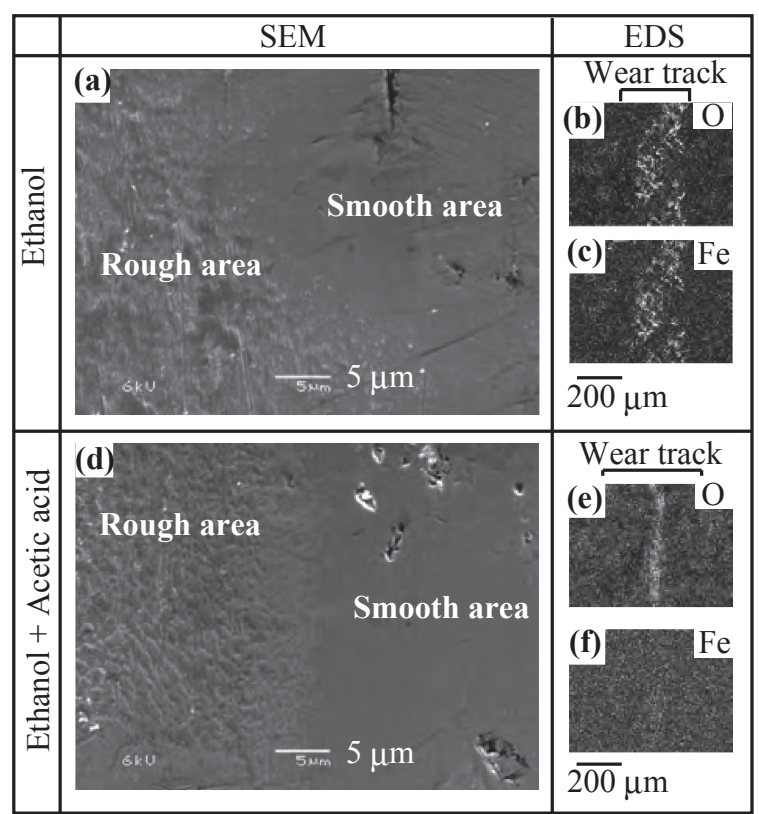

Fig. 11 SEM images and EDS maps of the surfaces of 5-10-85 composite disks: (a) SEM image, (b) O K $\alpha$ map and (c) Fe K $\alpha$ map of the disk worn in ethanol and (d) SEM image, (e) $\mathrm{O} \mathrm{K} \alpha$ map and (f) Fe $\mathrm{K} \alpha$ map of the disk worn in ethanol solution containing acetic acid. Brighter contrast in the EDS maps indicates a higher concentration of the element.

Table 5 Chemical compositions of the worn surfaces of disks of the titanium-based material.

\begin{tabular}{|c|c|c|c|c|c|c|c|}
\hline \multirow{2}{*}{ Material } & \multirow{2}{*}{ Lubricant } & \multirow{2}{*}{ Surface type } & \multicolumn{5}{|c|}{ Atomic ratio, /atomic $\%$} \\
\hline & & & $\mathrm{C}$ & $\mathrm{O}$ & $\mathrm{Si}$ & $\mathrm{Ti}$ & $\mathrm{Fe}$ \\
\hline \multirow{2}{*}{ Ti Metal } & Ethanol & & 1.06 & - & - & 98.94 & - \\
\hline & Ethanol + Acetic acid & & - & - & - & 99.91 & 0.09 \\
\hline \multirow{4}{*}{$\begin{array}{c}5-10-85 \\
\text { Composite }\end{array}$} & \multirow{2}{*}{ Ethanol } & rough & 0.75 & 34.31 & 2.05 & 58.22 & 4.67 \\
\hline & & smooth & - & - & 1.59 & 98.40 & 0.01 \\
\hline & \multirow{2}{*}{ Ethanol + Acetic acid } & rough & - & 30.24 & 0.79 & 67.86 & 1.11 \\
\hline & & smooth & - & - & 1.19 & 98.77 & 0.04 \\
\hline
\end{tabular}

disk in ethanol both with and without acetic acid (Figs. 12(a) and 12(b)). These results demonstrate that wear of titanium metal was hardly influenced by the addition of acetic acid and that mechanical wear such as severe adhesion and cutting was the primary wear mechanism of the titanium metal disk in ethanol and in an ethanol solution containing acetic acid.

Both smooth and rough areas can be seen on the surfaces of 5-10-85 composite disks worn in ethanol with and without acetic acid (Figs. 11(a) and 11(d)). On the wear track, there were some areas whose concentrations of $\mathrm{O}$ and $\mathrm{Fe}$ were higher than those of unworn surface (Figs. 11(b), 11(c), 11(e) and 11(f)). EDS analysis revealed that the rough areas contained high concentration of $\mathrm{O}$ and small amounts of $\mathrm{Fe}$ (Table 5). The binding energies of Ti $2 \mathrm{p}_{3 / 2}$ peak of $458.6 \pm$ $0.1 \mathrm{eV}$ and $\mathrm{O} 1 \mathrm{~s}$ peak of $530.4 \pm 0.1 \mathrm{eV}$ were detected in the XPS spectra of the wear tracks of the 5-10-85 composite disks worn in ethanol with and without acetic acid. These peaks were assigned to $\mathrm{TiO}_{2} \cdot{ }^{50}$ ) The thickness of the titanium oxide layer on the wear track was less than the range distance of the electron beam of EDS. ${ }^{51)}$ The elements both in the titanium oxide layer and in the substrate material were detected by EDS. Therefore, the atomic ratio of $\mathrm{O} / \mathrm{Ti}$ in the rough area was smaller than that of $\mathrm{TiO}_{2}$, i.e., 2. On the

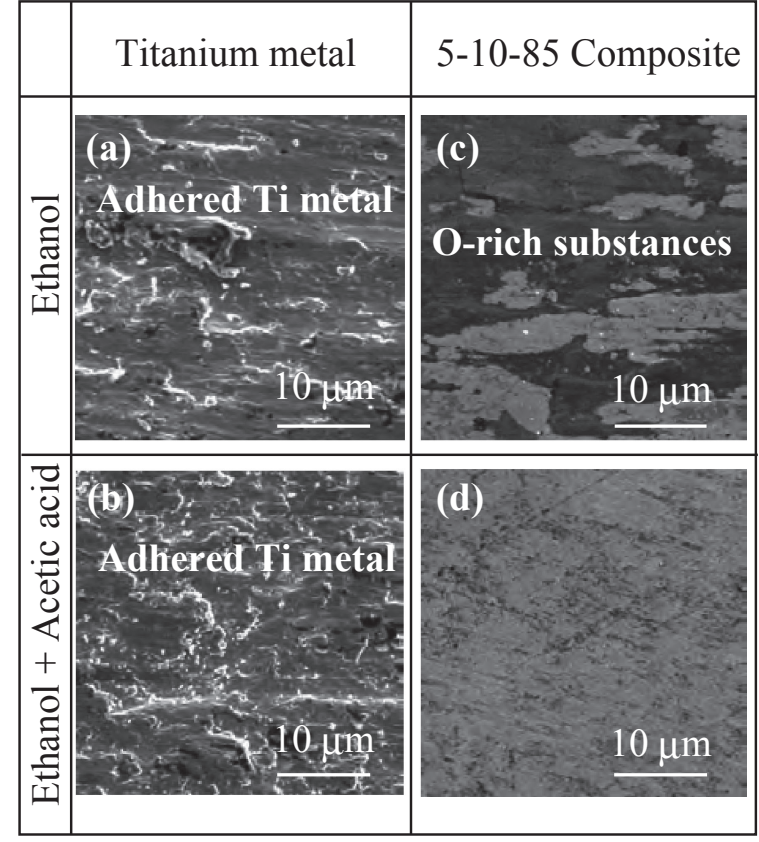

Fig. 12 SEM images of SUS440C stainless steel pins slid against titaniumbased materials: pins slid against titanium metal disk in (a) ethanol and (b) ethanol solution containing acetic acid and pins slid against 5-10-85 composite disk in (c) ethanol and (d) ethanol solution containing acetic acid.

surface of titanium-containing compounds slid in the presence of oxygen, titanium oxide $\left(\mathrm{TiO}_{2}\right)$ was formed by tribo-oxidation. ${ }^{52)}$ Titanium-containing compounds subjected to mechanical stimulation have also been found to react with alcohols to form titanium alkoxides. ${ }^{28,29,53,54)}$ The titanium alkoxides subsequently hydrolyze and condense to form a titanium oxide $\left(\mathrm{TiO}_{2}\right)$ gel with and without acetic acid. $^{28,29,53-58)}$ The increase in the $\mathrm{O}$ concentration in the rough areas of the worn surface of the 5-10-85 composite disk may have been caused by the formation of titanium oxide by the tribochemical reaction of the Ti component of the 5-10-85 composite with dissolved oxygen in ethanol and the ethanol itself. Films of titanium oxide and/or titanium oxide gel appear to have been present on the sliding surface of the 5-10-85 composite disks both in ethanol and in ethanol solution containing acetic acid. During sliding, the formation and removal of these films, i.e., tribochemical wear, seemed to occur.

Ti was hardly adhered on the SUS440C stainless steel pins slid against the 5-10-85 composite disks in ethanol both with and without acetic acid (Figs. 12(c) and (d)). O-rich substances, which might be iron oxide and/or chromium oxide, were observed on the surface of the SUS440C stainless steel pin slid against the 5-10-85 composite disk in ethanol (Fig. 12(c)). The surface of the SUS440C stainless steel pin slid against the 5-10-85 composite disk in ethanol solution containing acetic acid was smooth (Fig. 12(d)).

\subsection{The effect of acetic acid on wear behavior}

Electrolytes such as acetic acid are known to cause the electrochemical corrosion of metal materials in polar protic solvents. ${ }^{5)}$ The films made of iron oxides $\left(\mathrm{Fe}_{2} \mathrm{O}_{3}\right.$ and $\left.\mathrm{Fe}_{3} \mathrm{O}_{4}\right)$ on the cast iron, chromium oxide and iron oxide $\left(\mathrm{Cr}_{2} \mathrm{O}_{3}\right.$ and 
Table 6 Effects of acetic acid in the lubricant on wear of the test specimens.

\begin{tabular}{ll}
\hline \multicolumn{1}{c}{ Material } & \multicolumn{1}{c}{ Effect of acetic acid on wear } \\
\hline FC250 Cast iron & $\begin{array}{l}\text { Acetic acid caused anodic dissolution of bare metal of fresh } \\
\text { surface. }\end{array}$ \\
\hline Ti Metal & $\begin{array}{l}\text { Mechanical wear independent of acetic acid was } \\
\text { predominant. }\end{array}$ \\
\hline 5-10-85 Composite & $\begin{array}{l}\text { Tribochemically produced titanium oxide layer protected } \\
\text { sliding surface from acetic acid. }\end{array}$ \\
\hline
\end{tabular}

$\left.\mathrm{Fe}_{2} \mathrm{O}_{3}\right)$ on the stainless steel and titanium oxide $\left(\mathrm{TiO}_{2}\right)$ on the titanium-based materials acted as passivation layers that protected the metals from electrochemical corrosion such as anodic dissolution. ${ }^{13-17)}$ During the sliding motion applied in our experiment, these passivation films appear to have been removed repeatedly. After the passivation films were removed, the highly reactive fresh surfaces were exposed. ${ }^{59)}$ Then, the tribochemical reactions of bare metal with oxygen, ethanol and acetic acid took place on the fresh surface. Oxygen and ethanol formed metal oxide that contributed to repassivation. Acetic acid caused anodic dissolution of bare metal. Repassivation and anodic dissolution of the bare metal took place competitively on the sliding surface in ethanol solution containing acetic acid.

The addition of acetic acid resulted in increase of the wear of ferrous materials. On the sliding surface of the disk of ferrous materials in ethanol solution containing acetic acid, the anodic dissolution of iron seemed to dominant to repassivation. Therefore, wear caused by the anodic dissolution of iron took place on the sliding surface of the ferrous materials in ethanol solution containing acetic acid while wear caused by plastic deformation and oxidation of metals took place in ethanol.

On the other hand, the wear behavior of the titanium-based materials in ethanol was hardly affected by the addition of acetic acid. This is because the rate of growth of the repassivation film on titanium was higher than that on ferrous materials. ${ }^{60,61)}$ Mechanical wear such as severe adhesion and cutting occurred regardless of the tribochemical reactions on the sliding surfaces of titanium metal disks both in ethanol and in ethanol solution containing acetic acid. The tribochemical reactions of titanium component with oxygen and ethanol generated titanium oxide on the 5-10-85 composite disks in ethanol both with and without acetic acid. The titanium oxide films seemed to show good passivity. Therefore, the 5-10-85 composite exhibited good corrosion and wear resistance in ethanol with acetic acid.

The effects of acetic acid in the lubricant on wear of the test specimens are summarized in Table 6.

\section{Summary}

Our experimental results can be summarized as follows.

(1) The addition of acetic acid to the ethanol resulted in increase of the wear of ferrous materials (FC250 cast iron and SUS440C stainless steel). The sliding surfaces of the ferrous materials exhibited plastic deformation and oxidation of metals in ethanol. The dissolution of iron due to galvanic corrosion was evident on the surface of an FC250 cast iron disk immersed in an ethanol solution containing acetic acid. This process formed hollows around graphite and cementite protrusions. Sliding appeared to promote anodic dissolution of iron as well as fracture of the protruding cementite. The sliding surface of the SUS440C stainless steel in ethanol solution containing acetic acid exhibited wear caused by the anodic dissolution of iron.

(2) Acetic acid had essentially no effect on the wear behavior of titanium-based materials (titanium metal and the 5-10-85 composite) in ethanol. The wear volume of titanium metal disks in ethanol both with and without acetic acid was large because of mechanical wear such as severe adhesion and cutting. The wear of the 5-10-85 composite in ethanol with and without acetic acid was small. Tribochemical wear seemed to occur on the sliding surface of the 5-10-85 composite in ethanol both with and without acetic acid. The 5-10-85 composite showed good corrosion and wear resistance in ethanol solution containing acetic acid.

\section{REFERENCES}

1) I. Samusawa and K. Shiotani: Corros. Sci. 90 (2015) 266-275.

2) J.W. Sowards, T.S. Weeks and J.D. McColsky: Corros. Sci. 75 (2013) $415-425$.

3) X. Lou, D. Yang and P.M. Singh: J. Electrochem. Soc. 157 (2010) C86-C94.

4) X. Lou and P.M. Singh: Corros. Sci. 52 (2010) 2303-2315.

5) K. Aramaki: Zairyo-to-Kankyo 48 (1999) 190-198.

6) P. Hronsky: Corrosion 37 (1981) 161-170.

7) L.R. Goodman and P.M. Singh: Corros. Sci. 65 (2012) 238-248.

8) Y. Hibi and H. Mano: Tribology Online 11 (2016) 675-680.

9) S.H. Pine, J.B. Hendrickson, D.J. Cram and G.S. Hammond: Organic Chemistry International Student Edition Fourth Edition, (McGraw-Hill International Book Company, New York, 1981) p. 203.

10) T. Ohtsuka: Zairyo-to-Kankyo 63 (2014) 121-126.

11) K. Yonehiro, T. Nakata and H. Imai: J. JFS 75 (2003) 605-611.

12) T. Shimose, A. Takamura and S. Segawa: Corros. Eng. Jpn. 15 (1966) 49-55.

13) C.L. McBee and J. Kruger: Electrochim. Acta 17 (1972) 1337-1341.

14) N.E. Hakiki, S. Boudin, B. Rondot and M.D.C. Belo: Corros. Sci. 37 (1995) 1809-1822.

15) C.-O.A. Olsson and D. Landolt: Electrochim. Acta 48 (2003) 10931104.

16) E. Huttunen-Saarivirta, L. Kilpi, T.J. Hakala, L. Carpen and H. Ronkainen: Tribol. Int. 95 (2016) 358-371.

17) A. Asserghine, D. Filotas, B. Nemeth, L. Nagy and G. Nagy: Electrochem. Commun. 95 (2018) 1-4.

18) S.R. Nutt and A.W. Ruff: Wear of Materials, ed. by K.C. Ludema and R.G. Bayer, (American Society of Mechanical Engineers, New York, 1983) pp. 426-433.

19) K.G. Budinski: Wear of Materials, ed. by K.C. Ludema and R.G. Bayer (American Society of Mechanical Engineers, New York, 1991) pp. 289-299.

20) J.C. Oh, S. Lee and G.M. Golkovski: Metall. Mater. Trans. A 32 (2001) 2995-3005.

21) P. Jiang, X.L. He, X.X. Li, L.G. Yu and H.M. Wang: Surf. Coat. Technol. 130 (2000) 24-28.

22) J.A. Vreeling, V. Ocelik and J.M.T. De Hosson: Acta Mater. 50 (2002) 4913-4924.

23) Z.D. Cui, S.L. Zhu, H.C. Man and X.J. Yang: Surf. Coat. Technol. 190 (2005) 309-313.

24) V. Ocelík, D. Matthews and J.T.M. De Hosson: Surf. Coat. Technol. 197 (2005) 303-315.

25) D.E. Alman and J.A. Hawk: Wear 225-229 (1999) 629.

26) E. Pleshakov, Ya. Senyas'kyi and R. Fillip: Mater. Sci. 38 (2002) 646652.

27) Y. Hibi and T. Murakami: Tribology Online 3 (2008) 185-189. 
28) Y. Hibi, Y. Enomoto and S. Sasaki: J. Am. Ceram. Soc. 88 (2005) 470472.

29) Y. Hibi, Y. Enomoto and S. Sasaki: J. Surf. Sci. Soc. Jpn 23 (2002) 404-410.

30) Y. Hibi, Y. Enomoto, H. Sato and S. Sasaki: J. Am. Ceram. Soc. 85 (2002) 2373-2375

31) E. Kurosawa, T. Tsutsumi and T. Miyake: R\&D Kobe Steel Engineering Reports 67 (2018) 106-110.

32) K. Hayakawa: From Tech Review 26 (2016) 100-105.

33) National Astronomical Observatory: Chronological Scientific Tables 2007, (Maruzen Co., Ltd., Tokyo, 2006) p. 375.

34) Y. Hibi and K. Miyake: Tribology Online 13 (2018) 57-66.

35) M.B. Peterson and W.O. Winer: Wear Control Handbook, (American Society of Mechanical Engineers, New York, 1980) p. 451.

36) A.E. Morgan, E.K. Broadbent, K.N. Ritz, D.K. Sadana and B.J. Burrow: J. Appl. Phys. 64 (1988) 344-353.

37) M. Maeda, R. Oomoto, T. Shibayanagi and M. Naka: Metall. Mater. Trans. A 34 (2003) 1647-1656.

38) M.S. Selamat, L.M. Watson and T.N. Baker: J. Mater. Process. Technol. 142 (2003) 725-737.

39) S. Veprek, A. Niederhofer, K. Moto, T. Bolom, H.-D. Mannling, P. Nesladek, G. Dollinger and A. Bergmaier: Surf. Coat. Technol. 133134 (2000) 152-159.

40) B.K. Prasad: Wear 260 (2006) 1333-1341.

41) S.M. Hsu, J. Zhang and Z. Yin: Tribol. Lett. 13 (2002) 131-139.

42) N. Chelliah and S.V. Kailas: Wear 266 (2009) 704-712.

43) J.R. Gomes, A.S. Miranda, R.F. Silva and J.M. Vieira: J. Am. Ceram. Soc. 82 (1999) 953-960.

44) T.F.J. Quinn: Tribol. Int. 16 (1983) 257-271.

45) Y.C. Liu, J.M. Schissler and T.G. Mathia: Tribol. Int. 28 (1995) 433 438.
46) M. Sakakibara, N. Saito, H. Nishihara and K. Aramaki: Corros. Sci. 34 (1993) 391-402.

47) J. Banaś, B. Stypuła, K. Banaś, J. Światowska-Mrowiecka, M. Starowicz and U. Lelek-Borkowska: J. Solid State Electrochem. 13 (2009) 1669-1679

48) T. Ogihara, M. Yabuuchi, T. Yanagawa, N. Ogata, K. Yoshida, N. Nagata, K. Ogawa and U. Maeda: Adv. Powder Technol. 8 (1997) $73-$ 84.

49) T. Sato, T. Nishizawa and J. Ishikawa: J. Japan Inst. Metals 23 (1959) 403-407.

50) M.V. Kuznetsov, J.F. Zhuravlev and V.A. Gubanov: J. Electron Spectrosc. Relat. Phenom. 58 (1992) 169-176.

51) J.A. Gledhill: J. Phys. A 6 (1973) 1420-1428.

52) P. La, J. Ma, Y.T. Zhu, J. Yang, W. Liu, Q. Xue and R.Z. Valiev: Acta Mater. 53 (2005) 5167-5173.

53) Y. Hibi, Y. Enomoto and A. Tanaka: J. Mater. Sci. Lett. 19 (2000) 1809-1812.

54) Y. Hibi and S. Sasaki: J. Surf. Sci. Soc. Jpn 25 (2004) 416-421.

55) K. Kamiya, K. Tanimoto and T. Yoko: J. Mater. Sci. Lett. 5 (1986) $402-404$.

56) S. Doeuff, M. Henry, C. Sanchez and J. Livage: J. Non-Cryst. Solids 89 (1987) 206-216.

57) D.P. Birnie, III and N.J. Bendzko: Mater. Chem. Phys. 59 (1999) 2635.

58) R. Parra, M.S. Goes, M.S. Castro, E. Longo, P.R. Bueno and J.A. Varela: Chem. Mater. 20 (2008) 143-150.

59) K. Ueda, K. Nakaie, S. Namba, T. Yoneda, K. Ishimizu and T. Narushima: Mater. Trans. 54 (2013) 1281-1287.

60) P. Henry, J. Takadoum and P. Bercot: Corros. Sci. 51 (2009) 13081314.

61) S. Frangini and C. Piconi: Mater. Corros. 52 (2001) 372-380. 